\title{
An Investigation of Date of Birth in the Incidence of Learning Disabilities
}

By: Edward A. Polloway and J. David Smith

Polloway, E. A., \& Smith, J. D. (1986). An investigation of date of birth in the incidence of learning disabilities. Special Services in the Schools, 2 77-86.

Made available courtesy of HAWORTH PRESS:

http://www.haworthpress.com/store/product.asp?sid=6JFNXNKNX44U8LVSCVUQ1LSQT92F

$\underline{58 \mathrm{~J} 8 \& \text { sku }=\mathrm{J} 008 \& \text { AuthType }=4}$

***Note: Figures may be missing from this format of the document

\begin{abstract}
:
The literature on the epidemiology of various handicapping conditions reflects the interest that researchers have had in the possible role of seasonal variations as correlates of the incidence of specific disabilities. This study investigated the possible relationship between individuals' month and season of birth and their subsequent identification as learning disabled (LD). Birthdate records of $583 \mathrm{LD}$ and 7911 non-LD students in grades K-12 were compared to determine whether monthly or seasonal patterns unique to LD students existed. Non-parametric statistical analysis of the data indicated non-significant differences in birthdate patterns between these two populations. Discussion focuses on the need for caution in presuming the validity of a birthdate effect.

\section{Article:}

The study of the etiology of learning disabilities has frequently lacked scientific precision as researchers have sought to discover factors that may contribute to the prevalence of this handicapping condition. Research has been problematic in particular because of the myriad of possible causes and correlates that have been associated with this area of exceptionality. Logically, all of the biological, psychological, socio-cultural and educational variables possibly contributing to learning disabilities must be considered in examining etiological sources. At times, however, attention in the field has tended to focus on one variable in relative isolation from the possible interaction of other variables.
\end{abstract}

An etiological question that has periodically attracted the attention of researchers is the relationship between season of birth and handicapping conditions. Season or specific month of birth has been scrutinized in two major ways. Concern has been focused on the possibility that children born in a given month may be at increased risk for school-related difficulties due to seasonal variations in prenatal and perinatal factors. This hypothesis might be considered an extension of Knobloch and Pasamanick's (1959, Pasamanick \& Knobloch, 1973) "continuum of reproductive casualty." This concept suggests a possible range of effects from fetal or neonatal death, to cerebral palsy and epilepsy, to learning and behavioral difficulties resulting from minor cerebral damage. Various learning disorders and problems could then be seen as resulting from the effects of reproductive inefficiency (Jordan, 1972); date of birth could be among those factors warranting consideration. 
A second premise is that births occurring later in the calendar year predispose children to learning problems. This assumption attributes difficulties in school to maturational deficiencies resulting from the fact that these children are younger upon entry into school. The implication is that deficits in learning readiness are the causative agents for failure in subsequent academic subject areas. In order for either of these two premises to be validated, prevalence data on children later identified as disabled would need to be skewed toward increased number of births in a given month or season.

As cause or correlate, seasonal variations in birth rates have been associated with a number of handicapping conditions. For example, Pinter and Forlano (1943) reviewed eleven studies and reported lower levels of intellectual functioning for individuals born in winter and fall as compared to spring and summer. These findings appear consistent with those of Martindale and Black (1970) who reported that summer-born children had significantly higher IQs than did those born in the winter. However the definitions of seasons in these studies differed and thus hinder interpretation and generalization. In addition, Martindale and Black reported that mean IQ scores were lowest for individuals born in July, and therefore they hypothesized that moderate temperatures at the time of birth were more often associated with high IQ and temperature extremes with lower IQ. Finally, Knobloch and Pasamanick (1958) found that significantly more mentally retarded persons were born in the first three months of the year. Therefore, although seasonal patterns have been associated with intellectual level, the relationship is neither entirely clear nor consistent.

Other handicapping conditions have also been investigated. Wehrung and Hay (1970) researched the relationship between fifteen congential malformations and season of birth. Of these only three (cleft lip or cleft palate, hypospadias, and positional foot defects) evidenced significant seasonal patterns with incidence rates generally found to be higher in the spring. Torrey, Toney and Peterson (1977) reported that birth month figures for schizophrenia reflected higher levels in December through May, with peaks in March and April. Thus again, although seasonal variations have been reported, consistent patterns have not been found in comparisons of the occurrence of various disabilities.

Research in the area of learning disabilities has primarily focused on the question of late calendar births and subsequent readiness for school (e.g., Di Pasquale, Moule \& Flewelling, 1980; Donofrio, 1977). Limited attention, however, has been given to possible relationships with specific prenatal and perinatal factors. Black (1973) reported that learning disabled (LD) children born in warmer months (May-October) had significantly higher IQs than did those born in the colder months (November-April). Diamond (1983) researched birthdate patterns in Hawaii and reported a gradual increase in the incidence of learning disabilities between the beginning and end of the year. She postulated that immaturity was an insufficient explanation for these findings and rather theorized that they were due to maternal or prenatal disease and/or nutrition. Badian (1984) also dealt with the hypothesis that high temperatures near the time of birth would be associated with learning deficits, especially in reading. She reported that prevalence rates for reading disabilities in boys born in the hottest months (July, August) in her geographical region (Massachusetts) was 5.5 times greater than for all subjects born in the other ten months. She offered several rationales for this finding including hot temperature at birth acting as a final 
perinatal insult to a child already at risk and sensitivity of the fetus conceived during the winter to maternal dietary deficiencies and possible holiday alcohol excesses.

The purpose of this study was to further investigate the possible relationship between seasonal variations and the occurrence of learning disabilities. Given the inconsistency in the patterns identified in previous research, any conclusions drawn have been perforce tentative and clearly in need of additional investigation. The current study represents an analysis of month and season of birth as a correlate of learning disabilities. The rationale for such an inquiry was well-stated by Wehrung and Hay (1970): "if a seasonal trend can be demonstrated for a malformation, then we can look for concommitant trends in other factors" (p. 30).

\section{METHOD}

\section{Subjects}

Students selected for this study were learning disabled children and adolescents within a rural/suburban school division in central Virginia. Records of the 583 students who comprised the total LD population for grades K-12 were studied; LD students represented $6.86 \%$ of the reported student enrollment within this school system.

Eligibility guidelines used for placement in learning disabilities programs in the system were consistent with the standards of Public Law 94-142 as implemented by the Commonwealth of Virginia (Virginia Department of Education, 1980). The following specific criteria were used as a basis for identification:

1. The child does not achieve commensurate with his or her age and ability levels in one or more of the areas listed (e.g., oral expression, listening comprehension, written expression, basic reading skill, reading comprehension, and mathematics calculation or reasoning), when provided with learning experiences appropriate for the child's age and ability levels.

2. The team finds that a child has a severe discrepancy between achievement and intellectual ability in one or more of the ... areas [listed above]. (p. 43)

\section{Procedure}

Records for each identified LD student were reviewed to determine month of birth. Data were then summarized by frequency by month. For purposes of comparison with data from the general population, birthdate records of all students enrolled within the school system were also summarized in similar fashion. In addition local hospital birth records were reviewed to evaluate any distinctive regional trends.

\section{RESULTS}

The incidence of births per month for learning disabled students as a percentage of data from the general school population is depicted in Figure 1. No apparent seasonal pattern can be discerned from the graph that would correspond either, for example, to the curvilinear relationship reported by Badian (1984) (i.e., prevalence decreasing in cold and moderate temperature months and increasing dramatically during hot months) or to the gradual increase through the year as reported by Diamond (1983). Although in the present study July was the modal birth month for LD students' , there was little numerical difference between that month and several others (e.g., 
November, September). The greatest apparent variance is between January and the other eleven months due to the unusually small percentage of children born in that month who were subsequently identified as LD.

Due to the fact that nominal data were to be analyzed in this study, a two sample chi square test (Siegel, 1956) was used to determine if significant differences existed between LD and non-LD groups in monthly birth patterns. The analysis (Bolding, 1984) of the data indicated nonsignificant differences with $\mathrm{x}^{2}=14.56, \mathrm{df}=11$ and $\mathrm{p} .2033$. $^{2,3}$

Given the fact that the analysis of monthly patterns could potentially have failed to detect the influence of possible seasonal variables (e.g., temperature trends, nutritional habits), a seasonal analysis was also undertaken similar to the one reported by Badian (1984). Seasons were established which reflected monthly groupings with comparable temperature ranges. Mean monthly temperatures reported by the area office of the US Weather Service are reported in Table 1. Based on these data, four groupings were used: (a) December, January, and February; (b) March, April and May; (c) June, July and August; and, (d) September, October, and November. This arrangement allowed for increased homogeneity in temperature while also reflecting possible chronological influences indicative of a potential birthdate effect.

The two way chi square test was used to analyze the data on seasons with the obtained valued of $\mathrm{X}^{2}=6.41$ being non-significant with $\mathrm{p}=.933, \mathrm{df}=3$. Therefore, as with the question of monthly variations, the hypothesis of seasonal differences between LD and non-LD students could not be accepted. 


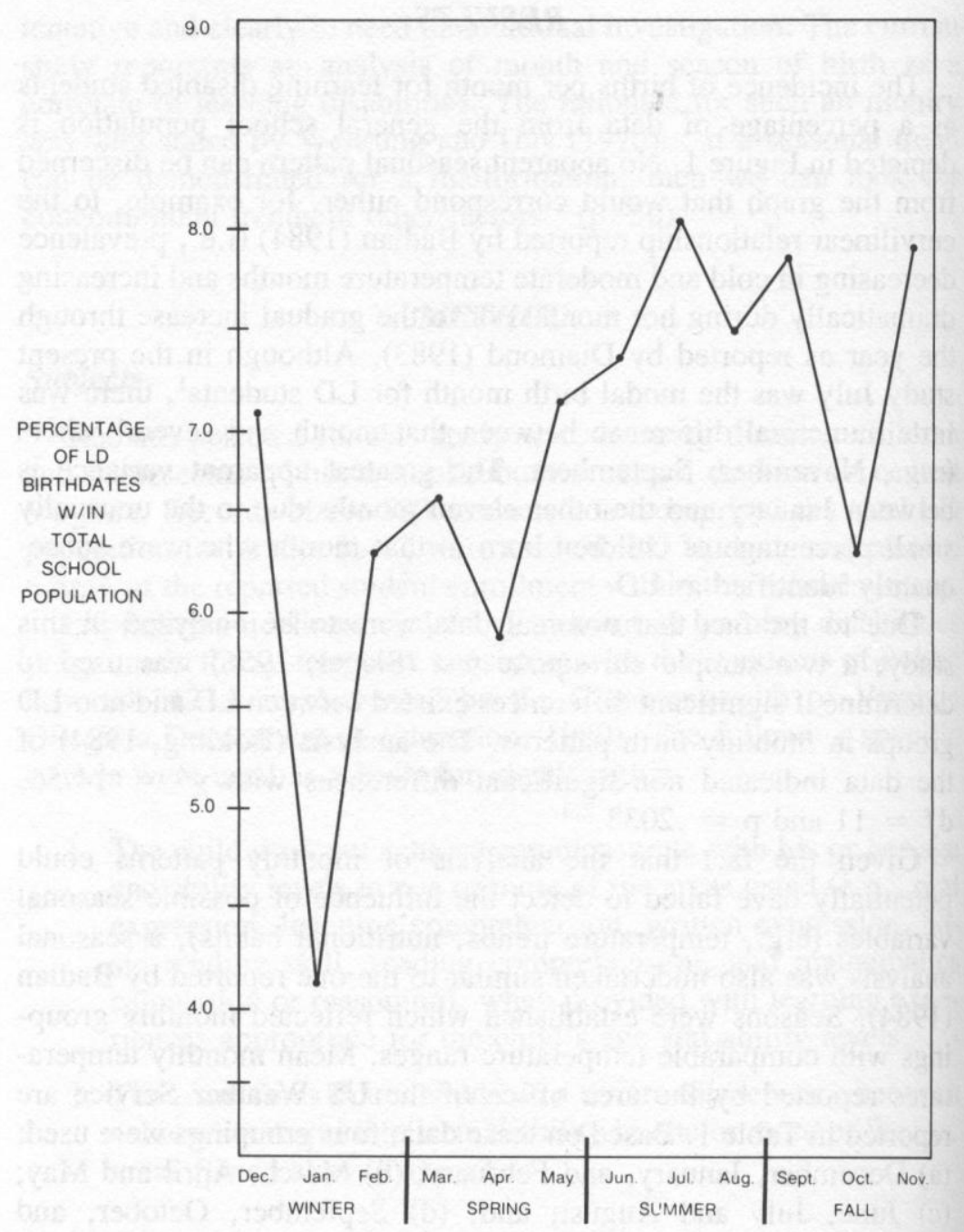

Figure 1. The prevalence of birthdates of LD students by month as a percentage of monthly birthdate totals for all students.

\section{DISCUSSION}

Data obtained from birthdate records of learning disabled students within this population sample do not support the hypothesis that specific months or seasons are related to subsequent disabilities in school. Despite the inherent appeal of seasonal explanations based on nutritional habits and temperature extremes as possible causal agents or at least correlates of learning disabilities, the relationship in this case appears to be at best a weak one. Although there clearly has been empirical support for links between diet and nutrition and brain development (e.g., Cravioto, 1973; Hallahan \& Cruickshank, 1973; Knobloch \& Pasamanick, 1958), and between hyperthermia (from fevers) and retardation (e.g., Smith, Clarren, \& Harvey, 1978), presumptions that consequences of poor nutrition or hyperthermia can be simply associated with birthdate is not justified by these data. 
Assumptions of developmental lag or lack of readiness based on chronological age at the time of school entrance have been posited by many researchers (e.g., Donofrio, 1977; DiPasquale et al., 1980). However, given that neither monthly nor seasonal variations

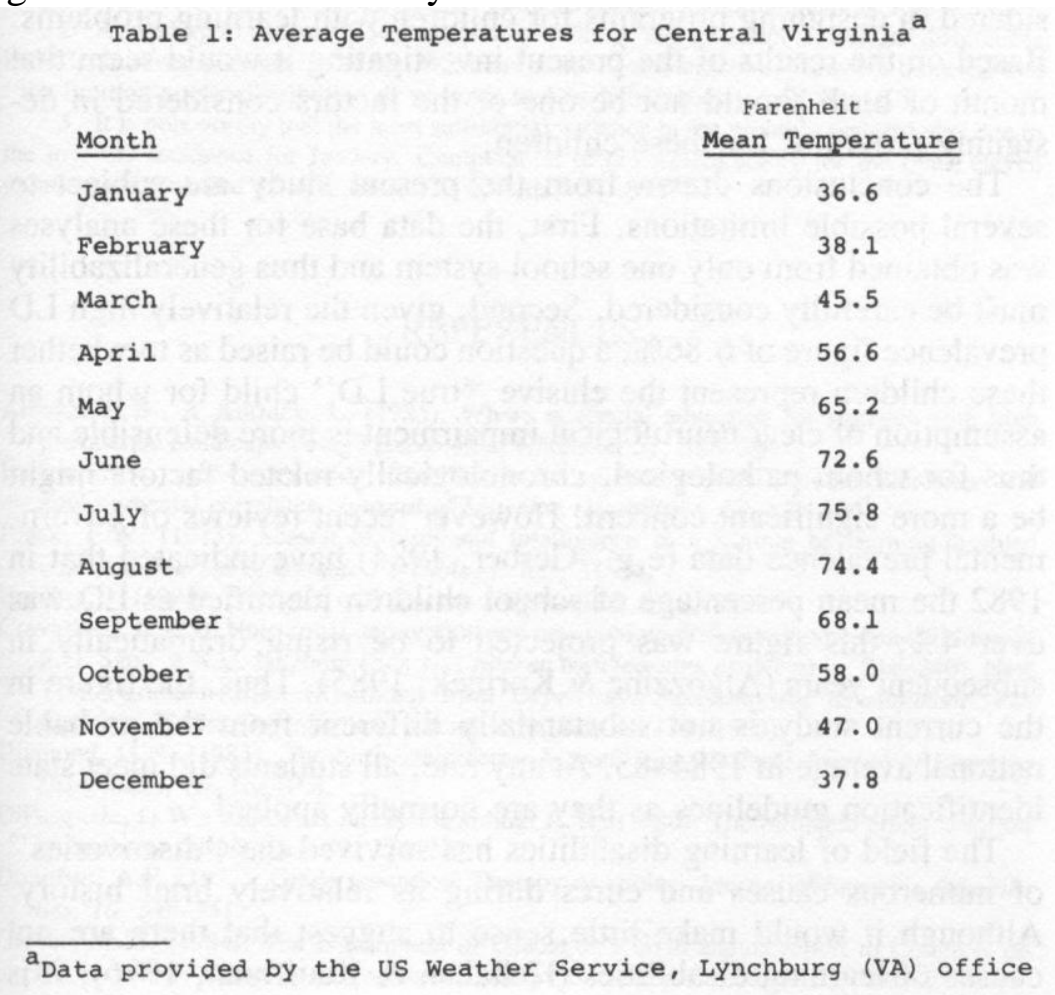

for LD students were significantly different than for the general school population, it is important to note that the current study would not lend support to this hypothesis. Observation solely of the frequency counts for the latter half of the year indicate that more LD students have later birthdates; however, this trend was also found in the data from the general school populations as well as in local hospital records.

With both monthly and seasonal birthdates for LD children not differing significantly from that of the general school population in this study, there is an obvious need for caution in terms of judgments about the role of such patterns within the epidemiology of learning disabilities. There continues to be a danger in the search for cause if it leads to speculative action and unsupported presumptions. The concept of a "birthdate effect" should be clearly supported by research before resulting in the addition of another non-validated precept to the field of learning disabilities. Gredler (1980a, 1980b) has stated that multiple causes of learning problems should be considered in designing programs for children with learning problems. Based on the results of the present investigating it would seem that month of birth should not be one of the factors considered in designing programs for these children.

The conclusions drawn from the present study are subject to several possible limitations. First, the data base for these analyses was obtained from only one school system and thus generalizability must be carefully considered. Second, given the relatively high LD prevalence figure of $6.86 \%$, a question could be raised as to whether these children represent the elusive "true LD" child for whom an assumption of clear neurological impairment is more defensible and thus for whom pathological, chronologically-related factors might be a more significant 
concern. However recent reviews of governmental prevalence data (e.g., Gerber, 1984) have indicated that in 1982 the mean percentage of school children identified as LD was over 4\%; this figure was projected to be rising dramatically in subsequent years (Algozzine \& Korinek, 1985). Thus, the figure in the current study is not substantially different from the probable national average in 1984-85. At any rate, all students did meet state identification guidelines as they are normally applied.

The field of learning disabilities has survived the "discoveries" of numerous causes and cures during its relatively brief history. Although it would make little sense to suggest that there are not causes of learning disabilities (Hallahan \& Kauffman, 1976), it is imperative that hypothesized etiological agents are empirically validated. Given that learning disabilities are "presumed to be due to central nervous system dysfunction", (Hammill, Leigh, McNutt, \& Larsen, 1981, p. 336), there certainly is a need for further research that leads to the identification of factors that do and do not contribute to learning disabilities. In regard to identifying factors that do not contribute to learning disabilities, it may be advantageous for the present investigation to be replicated in other states. Such replication may help determine the generalizability of the findings.

\section{ENDNOTES}

1. These data compare favorably with information obtained from a review of the hospital records of the facility currently handling in excess of $92 \%$ of the births in this area. Over the past twenty years, births within the general population were consistently more numerous in the second half of the year (R. Crowder, personal communication, July 6 , 1984).

2. According to Siegel (1956), the power of the $x^{2}$ test to detect significant differences is difficult to compute given the fact that there is no clear alternative. However he noted that "the limiting power distribution of $\mathrm{x}^{2}$ tends to I as $\mathrm{N}$ becomes large" (p. 110).

3. It is noteworthy that the most substantial variance in the monthly patterns was due to the low LD incidence for January. Computation of chi square solely for the other eleven months indicated that $\mathrm{x}^{2}=5.65$ for $10 \mathrm{df}$ with $\mathrm{p}=.8437$.

\section{REFERENCES}

Algozzine, B., \& Korniek, L. (1985). Where is special education for students with high prevalence handicaps going? Exceptional Children, 51, 388-394.

Badian, N.A. (1984). Reading disability in an epidemiological context: Incidence and environmental correlates. Journal of Learning Disabilities, 17, 129-136.

Black, F.W. (1973). Season of birth and intelligence in a sample of learning-disabled children. Journal of Genetic Psychology, 123, 31-34.

Bolding, J. (1984). Statistics with finesse. Fayetteville, AR: Author.

Cravioto, J. (1973). Nutritional deprivation and psychobiological development in children. In S.G. Sapir \& A.C. Nitzburg (Eds.)., Children with learning problems (p. 218-240). New York: Brunner-Mazel (Reprinted from Deprivation-Psychological development, Pan American Health Organization, Scientific Publication 134, 1966).

Diamond, G.H. (1983). The birthdate effect-A motivational effect? Journal of Learning Disabilities, 16, 161-164. 
DiPasquale, G.W., Moule, A.D., \& Fleweling, R.W. (1980). The birthdate effect. Journal of Learning Disabilities, 13, 234-238.

Donofrio, A.F. (1977). Grade repetition: Therapy of choice. Journal of Learning Disabilities, 10, 349-351.

Gerber, M.M. (1984). The Department of Education's sixth annual report to Congress on PL 94-142: Is Congress getting the full story? Exceptional Children, 51, 209-224.

Gredler, G.R. (1980a). The birthdate effect: Fact or artifact? Journal of Learning Disabilities, 13, 239-242.

Gredler, G.R. (1980b). Cumulative retention rate as an index of academic progress: A third look. Journal of Learning Disabilities, 13, 245-248.

Hallahan, D.P., \& Cruickshank, W.M. (1973). Psychoeducational foundations of learning disabilities. Englewood Cliffs, N.J.: Prentice-Hall.

Hallahan, D.P., \& Kauffman, J.M. (1976). Introduction to learning disabilities: A psychobehavioral approach. Englewood Cliffs, N.J.: Prentice-Hall.

Hammill, D.D., Leigh, J.E., McNutt, G., \& Larsen, S.C. (1981). A new definition of learning disabilities. Learning Disability Quarterly, 4, 336-342.

Jordan, T.E. (1972). The mentally retarded (3rd Ed.). Columbus, Ohio: Charles E. Merrill. Knobloch, H., \& Pasamanick, B. (1958). Seasonal variation in the births of the mentally deficient. American Journal of Public Health, 48, 1201-1208.

Knobloch, H., \& Pasamanick, B. (1959). Syndrome of minimal cerebral damage in infancy. Journal of the American Medical Association, 170, 1384-1387.

Martindale, C., \& Black, W. (1970). Season of birth and intelligence. Journal of Genetic Psychology, 117, 137-138.

Pasamanick, B., \& Knobloch, H. (1973). The epidemiology of reproductive casualty. In S.G. Sapir \& A.C. Nitzburg (Eds.), Children with learning problems (p. 193-199). New York:

Brunner-Mazel (Reprinted from D.A. VanKrevelen (Ed.) Child Psychiatry, 1964, 108-115). Pintner, R., \& Forlano, G. (1943). Season of birth and mental differences. Psychological Bulletin, 40, 25-35.

Siegel, S. (1956). Non-parametric statistics for the behavioral sciences. New York: McGraw Hill.

Smith, D.W., Clarren, S.K., \& Harvey, M.A. (1978). Hyperthermia as a possible teratogenic agent. The Journal of Pediatrics, 92, 878-883.

Torrey, E.F., Torrey, B.B., \& Peterson, M.R. (1977). Seasonality of schizophrenic births in the United States. Archives of General Psychiatry, 34, 1065-1070.

Virginia Department of Education (1980). Guidelines for programs for students with specific learning disabilities in Virginia's public schools. Richmond: Author.

Wehrung, D.A., \& Hay, S. (1970). A study of seasonal incidence of congenital malformations in the United States. British Journal of Preventive and Social Medicine, 24, 24-32. 